\title{
Influência dos compostos fenólicos de especiarias sobre a lipoperoxidação e o perfil lipídico de tecidos de ratos ${ }^{1}$
}

\author{
influence of spices phenolic compounds on \\ lipoperoxidation and lipid profile of rats tissues
}

Ana Vládia Bandeira MOREIRA²

Jorge MANCINI-FILHO ${ }^{3}$

\section{RE S U M O}

\section{Objetivo}

Este trabalho avaliou o efeito antioxidante dos compostos fenólicos de uma mistura de especiarias (mostarda, canela e erva-doce) sobre o metabolismo dos ácidos graxos das séries $\omega 3$ e $\omega 6$.

\section{Métodos}

Ratos Wistar recém desmamados receberam dieta rica em gorduras essenciais e um chá de especiarias. Após 45 dias, os animais foram sacrificados e tiveram seus tecidos coletados para análise das substâncias reativas ao ácido tiobarbitúrico e perfil lipídico.

\section{Resultados}

O chá fornecido aos animais apresentou atividade antioxidante equivalente ao hidroxitolueno butilado. Foram identificados no chá, os ácidos fenólicos catecol, salićlico e caféico; as enzimas cicloxigenase e lipoxigenase foram inibidas pelos extratos ricos nestes ácidos fenólicos. O perfil de ácidos graxos apresenta diferença entre os grupos teste e controles. Todos os tecidos dos grupos teste apresentaram menores valores em lipoperoxidação, em comparação aos controles.

\footnotetext{
1 Artigo elaborado a partir da tese de A.V.B. MOREIRA, intitulada "Efeito antioxidante dos compostos fenólicos de especiarias sobre os ácidos graxos das séries $\omega 3 \omega 6$ ". Faculdade de Ciências Farmacêuticas, Universidade de São Paulo, 2003. 162p.

2 Departamento de Nutrição, Centro de Ciências da Saúde, Universidade Federal do Rio Grande do Norte. Av. General Cordeiro de Farias, s/n, Petrópolis, 59100-180, Natal, RN, Brasil. Correspondência para/Correspondence to: A.V.B. MOREIRA. E-mail: avbm@bol.com.br

${ }^{3}$ Departamento Ciência dos Alimentos e Nutrição Experimental, Faculdade de Ciências Farmacêuticas, Universidade de São Paulo, SP, Brasil. E-mail: jmancini@usp.br
} 


\section{Conclusão}

Estes dados sugerem, portanto, um efeito antioxidante das substâncias fenólicas identificadas na mistura das especiarias, sobre os ácidos graxos das séries $\omega 3$ e $\omega 6$.

Termos de indexação: antioxidantes, lipoperoxidação, perfil lipídico, lipoxigenase, compostos fenólicos, ratos, ácidos graxos.

\section{A B S T R A C T}

\section{Objective}

This work analyzed the influence of the phenolic compounds from a blend of spices (mustard, cinnamon and anise) on the $\omega 3$ and $\omega 6$ fatty acids metabolism.

\section{Methods}

Weaned Wistar rats received a diet rich in essencial lipids and an infusion of blended spices for 45 days. After that period, they were sacrificed their tissues were collected and analized for the TBARS and lipid profile by CGMS.

\section{Results}

The tea of spices showed an antioxidant activity equivalent to that of the butylated hydroxytoluene. The following phenolic acids were identified in the infusion, using mass chromatography: cathecol, salicilic and cafeic; Lipooxygenase and ciclooxigenase enzymes were inhbited by the phenolic acid extracts. It was observed that the total amount of the fatty acids found in the test's rat tissues was different from that found in tissues of the control group. Tissues from the experimental groups presented a lower level of lipid peroxidation than those of the respective control groups.

\section{Conclusion}

Therefore, such results suggest that, the phenolic substances identified in the spices had an antioxidant effect on the $\omega 3$ and $\omega 6$ fatty acids.

Index terms: antioxidants, lipoperoxidation, lipid profile, lipooxygenase, ciclooxigenase, phenolic compounds, rats, fatty acids.

\section{N T R O D U Ç Ã O}

Os ácidos graxos poliinsaturados constituem-se de duas famílias de ácidos graxos: $\omega 6$ e $\omega 3$, distintos pela localização da primeira dupla ligação contida na molécula a partir do grupo metil terminal do ácido graxo. O ácido linoléico pertence à família dos ácidos graxos $\omega 6$ e o ácido $\alpha$-linolênico, dos ácidos graxos $\omega 3$. Estes ácidos graxos poliinsaturados não podem ser sintetizados pelo organismo humano. Eles são ácidos graxos essenciais que devem ser obtidos pela dieta. Ambas as famílias encontram-se amplamente distribuídas na natureza. Ácido linoléico é encontrado em sementes de muitas plantas com a exceção do côco, cacau e palma. Já o ácido $\alpha$-linolênico está largamente presente no cloroplasto de vegetais verdes frondosos, e em sementes de linhaça, sopa e canola. Algumas amêndoas, como as nozes inglesas, são muito ricas em ácido $\alpha$-linolênico, como também o óleo de peixe, fonte desse lípide ${ }^{1}$.

Os ácidos graxos poliinsaturados de cadeia longa são formados pelo alongamento e dessaturação dos ácidos linoléico e $\alpha$-linolênico. 
Quando eles são insuficientes na dieta, o corpo tem que sintetizá-los a partir de seus homólogos de maior número de carbonos, mas que não exista desequilíbrio nas proporções no regime alimentar entre as diferentes séries. Um excesso de ácido linoléico irá competir com o ácido $\alpha$-linolênico pelas dessaturases, tendo como possível conseqüência uma baixa produção de ácido eicosapentaenóico. Por esta razão recomenda-se manter uma proporção 6:1 - 10:1 entre a séries $\omega 6$ e $\omega 3$, e esta proporção pode ser encontrada no azeite de oliva'.

Lipoxigenases (LOX) e cicloxigenases (COX) são enzimas envolvidas na síntese de eicosanóides a partir do ácido araquidônico (AA). A oxigenação enzimática do ácido araquidônico ocorre preferencialmente nos carbonos 5, 12 ou 15, sendo catalizadas pelas enzimas 5, 12 ou 15 lipoxidases formando seus repectivos hidroperóxidos. Estes hidroperóxidos podem ser metabolizados a leucotrienos, lipoxinas e hepoxilinas. Um outro caminho metabólico é a transformação do AA em prostaglandinas pela catálise da endoperóxido sintase. Esta enzima é biofuncional e geralmente, na reação da COX inserem-se duas moléculas de oxigênio dentro da molécula do AA para formar a $\mathrm{PGG}_{2}$. Assim, oxigênio molecular é requisitado como outro substrato em ambas as enzimas da oxigenação do AA, a LOX e a COX.

Em 1978, dois conceitos importantes na formação de eicosanóides foram apresentados: (1) Moncada \& Vane ${ }^{2}$ mostraram que a parede vascular poderia utilizar endoperóxidos relacionados com a aderência de plaquetas para a formação de prostaciclinas; e, (2) Dyerberg et $a^{\beta}$. propuseram que o ácido eicosapentaenóico (EPA) somente de peixe ou óleo de peixe, por meio da formação de análogos ativos de prostaciclinas $\left(\mathrm{PGI}_{3}\right)$, mais tromboxanos $\left(\mathrm{TXA}_{3}\right)$, poderia produzir um estado antitrombótico e agir como protetor contra a doenças cardiovasculares.

Os antioxidantes podem ser divididos em duas classes: a dos com atividade enzimática e a dos sem essa atividade. Na primeira, estão os compostos capazes de bloquear a iniciação da oxidação, ou seja, as enzimas que removem as espécies reativas ao oxigênio. Na segunda classe, estão moléculas que interagem com as espécies radicalares e são consumidas durante a reação. Nesta classificação, incluem-se os antioxidantes naturais e sintéticos como os compostos fenólicos.

Pesquisas vêm sendo realizadas a fim de esclarecer o efeito dos antioxidantes naturais na inibição da biossíntese de eicosanóides, com a finalidade de uma resposta fisiológica. Guaiacol e eugenol, compostos fenólicos presentes em medicamentos dentários, apresentaram alta atividade inibitória da lipoxigenase, melhorando a resposta à ação inflamatória experimental em ratos experimentais. Em estudo realizado com azeite de oliva virgem foi verificado que compostos fenólicos presentes (oleuropeina, ácido caféico, tirosol e hidroxitirosol) foram capazes de inibir a 5-lipoxigenase de leucócitos de ratos. Este resultado confirma o de trabalho anterior, que verificou a ação dos flavonóides na inibição da lipoxigenase e da cicloxigenase ${ }^{4}$.

Certas especiarias e extratos de especiarias contêm componentes com atividade antioxidante. Tal atividade se confirma na aplicação destes componentes em diferentes preparações culinárias para intensificar as características organolépticas, aumentar a aceitabililidade e principalmente, melhorar a estabilidade oxidativa ${ }^{5}$.

Compostos que proporcionaram estabilidade oxidativa têm sido identificados em várias especiarias, tais como: alecrim, sálvia, tomilho, cravo-da-índia, dentre outras. Tais compostos que apresentam a propriedade antioxidante, são, principalmente, os compostos fenólicos ${ }^{6}$.

Compostos fenólicos são antioxidantes primários que agem como seqüestradores de radicais livres e bloqueadores de reações em cadeia. Eles estão largamente distribuídos na natureza e são derivados dos ácidos benzóico e cinâmico, bem como de flavonóides.

Estes compostos, principalmente glicosídeos de fenólicos, podem inibir, tanto a COX, como a LOX. Estes resultados justificam as 
pesquisas para avaliar o efeito inibitório de substâncias fenólicas sobre enzimas da biossíntese dos eicosanóides.

Dada a importância antioxidante dos compostos fenólicos para estudos in vitro e in vivo e devido à implicação destas substâncias na inibição de enzimas de substâncias de resposta inflamatória (eicosanóides), questiona-se como estas substâncias fenólicas, presentes em alimentos normalmente consumidos (especiarias), atuam no metabolismo de ácidos graxos das séries $\omega 3$ e $\omega 6$. Portanto, o objetivo do presente trabalho foi avaliar o efeito antioxidante de compostos fenólicos de especiarias sobre os ácidos graxos poliinsaturados das séries $\omega 3$ e $\omega 6$, ora por inibição de sua oxidação, ora por modificação do perfil lipídico dos tecidos de animais cuja alimentação foi suplementada com um chá de especiarias, ora por inibição das enzimas cicloxigenase e lipoxigenase.

\section{MATERIALE MÉTODOS}

As amostras de mostarda, canela e erva doce foram adquiridas no comércio local da cidade de São Paulo. Estas especiarias foram trituradas em mixer à temperatura ambiente e tamisadas (Tamis 32 Mesh). Depois de obtida a farinha de cada especiaria, foi elaborada uma mistura teste das três especiarias, para obtenção de extratos, frações fenólicas e do infuso a ser administrado aos animais. A proporção baseou-se no efeito sinergísitico apresentado pela mistura das três especiarias na proporção de 1:1:1, respeitando o perfil final dos ácidos fenólicos presentes (Tabela 1). A forma de consumo também pode estar relacionada com os efeitos dos compostos fenólicos de especiarias sobre o desenvolvimento de doenças ${ }^{7}$.

Para a elaboração das rações foram utilizados óleos comerciais, caseinato de cálcio (98\% de proteína) e ração padrão para roedores, e preparo segundo Guimarães et al. ${ }^{8}$. A complementação com maior quantidade de lipídeos e de proteínas, visou a padronização frente a trabalhos realizados anteriormente. Para a ração poliinsaturada $\omega 3$, adicionou-se óleo de peixe e caseinato de cálcio à ração padrão comercial para roedores (NUVILAB CR-1). O mesmo procedimento para a ração poliinsaturada $\omega 6$, porém a fonte lipídica foi substituída por óleo de soja. A composição foi determinada segundo metodologia descrita pela Association Office Analytical Chemists $^{9}$ (Tabela 1). Nesta tabela, também é possível identificar o perfil lipídico da ração fornecida aos animais, com concentrações distintas de ácidos graxos essenciais para cada ração.

Ratos Wistar machos, recém desmamados, com 28 dias, pesando entre 50-60g, foram mantidos em ambiente com temperatura controlada de $23^{\circ} \mathrm{C} \pm 2^{\circ} \mathrm{C}$ e um ciclo claro/escuro de 12 horas. Os animais foram divididos em 4 grupos de 10 animais. Foi chamado de grupo $\omega 3-C$, o grupo que recebeu dieta rica em óleo de peixe sem antioxidante e uma quantidade de uma solução de glicose, baseada na concentração de açúcares presentes na solução teste (extrato da mistura de especiarias). Foi denominado $\omega 3-\mathrm{E}$ o grupo suplementado com a mesma ração do grupo W3-C, mais o chá da mistura das especiarias (mostarda, canela e erva doce). Já, o grupo $\omega 6-C$ teve o mesmo tratamento do grupo $\omega 3-\mathrm{C}$, diferindo apenas no tipo de gordura oferecida, isto é, de óleo de soja. Houve a mesma modificação para o grupo $\omega 6-\mathrm{E}$, em relação ao grupo $\omega 3-E$, apenas diferindo a fonte lipídica.

Durante um período de 45 dias os animais foram mantidos em gaiolas coletivas com 5 animais cada, com água e ração ad libitum e, em horários fixos, foram administrados por gavagem os extratos e o placebo aos respectivos grupos.

O extrato administrado aos animais foi obtido da mistura proporcional das especiarias: mostarda, canela e erva-doce, na forma de um infuso (chá). A concentração de sólidos foi calculada para se estabelecer a concentração de 200 ppm em um volume de $200 \mu \mathrm{L}$ iniciais, administrados aos animais. O volume foi corrigido de acordo com o aumento de peso do animal. Já, 
a solução "placebo" foi obtida pelo cálculo baseado na concentração de açúcares solúveis presentes no chá, determinada pelo método de Dubois et al. ${ }^{10}$.

Os tecidos hepático, cardíaco, renal, cerebral e adiposo foram coletados e congelados em nitrogênio líquido, para posterior análise de ácidos graxos e atividade antioxidante. As condições de armazenamento foram as mesmas para o tecido plasmático.

As fezes dos animais foram coletadas e correspondentes à somatória do grupo de cinco animais, nos mesmos dias da coleta do sangue, com o objetivo de avaliar a absorção aparente de fenólicos, que foi determinada segundo o método espectrofotométrico proposto por Swain \& Hillis ${ }^{11}$. A coleta das fezes foi realizada por meio de uma pinça de aço inoxidável e feita uma média por grupo. A exclusão de gaiolas individuais se deu por estudos pilotos preliminares, durante os quais não foi observada uma diferença significativa no consumo e excreção entre os animais enquanto estes foram mantidos em gaiolas individuais; verificou-se ainda que os animais, quando mantidos em gaiolas coletivas, apresentaram menores níveis em peroxidação lipídica quando comparados aos animais mantidos em gaiolas individuais.

Tabela 1. Composição centesimal das rações experimentais.

\begin{tabular}{|c|c|c|}
\hline \multirow{2}{*}{ Constituintes } & \multicolumn{2}{|c|}{ Dietas } \\
\hline & Peixe $(\omega 3)$ & Soja $(\omega 6)$ \\
\hline Umidade & $4,21 \pm 0,05$ & $4,32 \pm 0,03$ \\
\hline Lípides & $18,84 \pm 1,21$ & $16,82 \pm 0,98$ \\
\hline Proteína & $26,20 \pm 2,34$ & $25,01 \pm 1,89$ \\
\hline Cinzas & $5,30 \pm 0,06$ & $4,75 \pm 0,52$ \\
\hline Fração Nifext & $45,45 \pm 3,24$ & $49,10 \pm 4,01$ \\
\hline \multirow{2}{*}{ Ácido graxo } & \multicolumn{2}{|c|}{ Concentração (\%) } \\
\hline & Peixe $(\omega 3)$ & Soja $(\omega 6)$ \\
\hline $10: 0$ & $0,45 \pm 0,05$ & $0,14 \pm 0,04$ \\
\hline $12: 0$ & $0,45 \pm 0,05$ & $0,30 \pm 0,21$ \\
\hline $15: 0$ & $0,67 \pm 0,02$ & nd \\
\hline $16: 0$ & $19,47 \pm 0,37$ & $12,25 \pm 0,08$ \\
\hline $17: 0$ & $0,79 \pm 0,10$ & nd \\
\hline $18: 0$ & $3,02 \pm 0,06$ & $3,22 \pm 0,04$ \\
\hline $20: 0$ & $4,58 \pm 0,10$ & nd \\
\hline$\sum$ Saturado & $29,43 \pm 0,70$ & $15,91 \pm 0,4$ \\
\hline $16: 1$ & $7,70 \pm 0,21$ & $0,34 \pm 0,01$ \\
\hline $17: 1$ & $0,89 \pm 0,10$ & nd \\
\hline $18: 1$ c6 & $14,27 \pm 0,16$ & $21,79 \pm 0,16$ \\
\hline $18: 1$ c9 & $2,47 \pm 0,02$ & $1,40 \pm 0,01$ \\
\hline $20: 1$ & $2,70 \pm 0,10$ & nd \\
\hline$\sum$ Monoinsaturado & $28,03 \pm 0,60$ & $23,53 \pm 0,20$ \\
\hline $18: 2$ & $10,75 \pm 0,29$ & $52,58 \pm 0,30$ \\
\hline $18: 3$ & $2,70 \pm 0,30$ & $4,72 \pm 0,12$ \\
\hline $20: 5$ & $11,05 \pm 0,26$ & $0,20 \pm 0,01$ \\
\hline $22: 6$ & $12,19 \pm 0,32$ & $0,13 \pm 0,03$ \\
\hline$\sum$ Poliinsaturado & $36,69 \pm 1,20$ & $57,63 \pm 0,60$ \\
\hline
\end{tabular}

$\mathrm{n}=6$; resultados expressos em MD $\pm \mathrm{DP}$. 
A ingestão e o peso dos animais foram monitorados durante todo o experimento, para a curva de ganho de peso e crescimento; e também, para obter-se o parâmetro para o cálculo dos extratos das especiarias a serem administrados. Os dados também foram obtidos por média do grupo.

O coeficiente de eficácia alimentar foi obtido através da fórmula:

$$
\text { CEA }=\frac{\text { ganho de peso do animal }(\mathrm{g})}{\text { consumo da ração(g) }}
$$

Os intestinos delgados dos animais foram coletados e, logo em seguida, retirados três segmentos de $1 \mathrm{~cm}$ das porções correspondentes ao duodeno, jejuno e íleo. Estes foram fixados em BOUIN por 24 horas, lavados em água corrente e em seguida, mantidos em álcool a 70\% até os processos de desidratação, diafanização e inclusão. Dos blocos de parafina preparados com as porções dos intestinos, foram obtidos dos cortes de $5 \mu \mathrm{m}$ de espessura e corados pela hematoxilina/ eosina $(\mathrm{HE})$.

A atividade antioxidante foi determinada in vitro pelo método descrito por Miller ${ }^{12}$.

Para análise cromatográfica dos tecidos dos animais, inicialmente foi obtida a fração lipídica pelo método de Folch et al. ${ }^{13}$ e em seguida, as amostras foram esterificadas pela técnica de Hartman \& Lago ${ }^{14}$. As análises foram realizadas em cromatógrafo a gás HP (modelo 6890 com detector de ionização de chama), conectado a um espectro de massa modelo 5972 SP, equipado em coluna capilar de sílica fundida, contendo polietileno glicol (Carbowax 30m), de $30 \mathrm{~m}$ de comprimento e 0,25mm de diâmetro interno. As condições cromatográficas se deram de acordo com a seguinte programação: temperatura da coluna isotérmica a $230^{\circ} \mathrm{C}$, temperatura do vaporizador $240^{\circ} \mathrm{C}$, gás de arraste, hidrogênio com fluxo de $1 \mathrm{~mL} /$ minutos. A identificação dos ácidos graxos das amostras foi feita pela utilização da biblioteca Niste do programa workstation 4.0, com o auxílio dos espectros obtidos por padrões Sigma®.
Há algumas metodologias descritas para a análise de compostos fenólicos por cromatografia a gás, baseada nas suas características de polaridade. Os ácidos fenólicos, muito presentes em especiarias, são substâncias que possuem alta polaridade e baixa pressão de vapor. Tais características levaram alguns autores a descrever processos distintos para derivatização e condições de análises cromatográficas, objetivando uma melhor técnica de isolamento e caracterização destes compostos. Neste trabalho, foi seguida a metodologia descrita por Dabrowski \& Sosulski ${ }^{15}$.

As condições cromatográficas para substâncias fenólicas seguiram os procedimentos descritos por Dabrowski \& Sosulski15. A coluna empregada foi a semipolar DB5 (J \& W®), com $25 \mathrm{~m}$ de comprimento por $0,25 \mathrm{~mm}$ de diâmetro. A programação de temperatura utilizada foi a seguinte: temperatura inicial de $112^{\circ} \mathrm{C}$, isotérmica por 3 minutos e programada de $112^{\circ} \mathrm{C}$ até $290^{\circ} \mathrm{C}$, a uma velocidade de aquecimento de $10^{\circ} \mathrm{C}$ por minuto; isotérmica a $290^{\circ} \mathrm{C}$, por 10 minutos. A temperatura da câmara injetora foi de $290^{\circ} \mathrm{C}$, a temperatura do detector, $300^{\circ} \mathrm{C}$ e o gás de arraste empregado foi o hidrogênio. A identificação dos ácidos fenólicos foi realizada com base nos tempos de retenção relativos das amostras, baseando-se no padrão interno (heptametildecanoato), na concentração dos compostos da solução padrão (Sigma) e, ainda, pela confirmação com os espectros de massa obtidos da biblioteca Phenolic - adquirida no decorrer do procedimento com cadastramento dos padrões, sendo estes incluídos no programa workstation 4.0.

A atividade de inibição das enzimas lipoxigenase e cicloxigenase foi avaliada pelas condições descritas em Survey ${ }^{16}$. LOX 1B da soja com 112 mil unidades por mg foi adquirida comercialmente da Sigma ${ }^{\circledR}$ e a obtenção da COX seguiu o método descrito por Schubert et al. ${ }^{17}$. O sobrenadante rico em COX teve o conteúdo protéico determinado pela metodologia de Bradford $^{18}$, expresso em $\mathrm{mg}$; pela mesma metodologia calcularam-se as alíquotas para igual, concentração da enzima LOX. 
Para determinação da medida das substâncias reativas ao ácido tiobarbitúrico, foi utilizado o método descrito por Winterbourn et al. ${ }^{19} \mathrm{com}$ pequenas adaptações nas quantidades utilizadas. Foram preparados homogenatos dos diferentes tecidos com tampão fosfato de sódio $10 \mathrm{mM}, \mathrm{pH}$ 7,4. Alíquotas de $0,3 \mathrm{~mL}$ do sobrenadante e $0,5 \mathrm{~mL}$ de tampão fosfato foram colocados em tubos. Em seguida, adicionou-se $\mathrm{HCl} 25 \%(\mathrm{v} / \mathrm{v}), 45 \mu \mathrm{L}$ de BHT etanólico $2 \%$ e $0,5 \mathrm{~mL}$ de TBA ( $1 \%$ p/ $\mathrm{v}$ em NaOH $0,05 \mathrm{M})$ e a solução foi agitada e levada ao banho-maria fervente por 10 minutos, seguido de resfriamento em banho de gelo; $1,5 \mathrm{~mL}$ de $\eta$-butanol foi acrescentado e logo em seguida, agitou-se. Após centrifugação a 4000 rpm, foram coletadas alíquotas da fase superior para serem analisadas espectrofotometricamente a um comprimento de onda de 532 a um branco contendo apenas as soluções do ensaio.

Para obtenção dos cálculos foi realizada uma curva padrão com 1, 1', 3, 3' tetramethoxipropano $\left(6 \times 10^{-6} \mathrm{~mol} / \mathrm{L}\right)$ e uma curva padrão de proteína com solução padrão de albumina, com o fim de os resultados serem expressos em $\mu \mathrm{Mol}$ MDA/mg Prot.

Para as variáveis estudadas foram utilizados os seguintes procedimentos estatísticos: (1) análise unidimensional; (2) análise de variância com efeitos fixos; (3) comparações múltiplas. Os programas computacionais utilizados foram o Microsoft Excel for Windows, versão 97 e minitab for Windows, versão 13.1.

Em todas as análises descritas anteriormente, considerou-se um nível de significância de $5 \%$. Os intervalos foram de $95 \%$ de confiança no modelo tipo Box-Plot que utiliza a mediana, intervalos de confiança e permite avaliar a variância dos grupos mediante a dimensão de suas caixas.

\section{RESULTADOS E DISCUSSÃO}

Os compostos fenólicos, sendo um dos maiores grupos de componentes dietéticos não essenciais, têm suas pesquisas justificadas por estarem associados à inibição de doenças crônico-degenerativas, como aterosclerose e câncer. A bioatividade dos fenólicos pode estar relacionada com o potencial antioxidante destes compostos, aos quais são atribuídas as seguintes características: quelar metais, inibir a LOX e seqüestrar radicais livres. Contudo, os compostos fenólicos podem também promover reação oxidativa in vitro, agindo como pró-oxidantes, ao atuarem sobre metais, reduzindo-os e aumentando a formação de radicais livres e peróxidos ${ }^{17}$.

As propriedades antioxidantes de várias ervas e especiarias estão correlacionadas com a sua ação junto ao processo de peroxidação lipídica em alimentos ${ }^{20}$. Com esta abordagem, há estudo relatando a atividade antioxidante destes vegetais constituídos de compostos fenólicos que possuem grupos hidroxi21

A mistura das três especiarias apresentou inibição significativa da oxidação nos três extratos, resultados estes mais evidentes nos chás da mistura teste, os quais demonstraram melhor atividade antioxidante a 200 ppm, com 89,10\% de inibição da oxidação, sem diferença significativa para atividade do mesmo extrato a 100 ppm (87,13\%) e atividade antioxidante superiores à dos extratos de cada especiaria (Figura 1A).

Para se obter um perfil de substâncias fenólicas é necessário extrair estas substâncias de maneira que estas possam ser identificadas e servir de parâmetro para a discussão segura dos resultados das matérias primas a serem analisadas (Tabela 2). Assim, o ácido salicílico foi o composto fenólico presente em todas as especiarias e com concentrações superiores aos demais compostos identificados. Os demais foram: catecol, hidroquinona, gliciteína, glicitina, trans-cinâmico, pirogalol, $\rho$-hidroxibenzóico, gentíssico, o-cumárico, protocatequínico, $\rho$-cumárico, silibinina, gálico, ferúlico, caféico, sináptico, rutina, revesratrol, naringerina, epicatequina, catequina, hesperitina, epilocatequina e clorogênico.

A despeito do perfil de substâncias fenólicas em especiarias, houve uma homogeneidade dos 
demais compostos identificados nas especiarias em questão, em concordância com resultados descritos nos poucos dados da literatura. Destacaram-se: os ácidos salicílico, caféico e catecol (Tabela 2), como também derivados cinâmicos, benzóicos e alguns flavonóides complexos.

Este efeito inibitório também foi observado no ensaio biológico quando foi verificado que ocorreu uma diminuição significativa da peroxidação lipídica em todos os tecidos avaliados dos animais que receberam o extrato (chá da mistura das especiarias), refletindo-se no perfil lipídico, principalmente, no percentual de incorporação dos ácidos graxos poliinsaturados essenciais (Tabela 3).
Mediante a composição das rações administradas aos animais, foi possível obter, após 45 dias de tratamento, a peroxidação lipídica dos tecidos dos animais assim como dados pontuais do perfil lipídico (Tabela 3).

Tem-se o conhecimento de que diferentes tecidos metabolizam preferencialmente certos ácidos graxos e, com isso, pode-se ter uma maior ou menor mobilização de um determinado ácido graxo, segundo estes parâmetros: 1) ser fornecido na dieta, 2) oferecerem-se outros componentes que podem influenciar no seu percentual de incorporação, como os antioxidantes dietéticos, 3) ser afetado por fatores externos, como situações de estresse e doenças.

Tabela 2. Identificação e quantificação dos compostos nas frações fenólicas em especiarias.

\begin{tabular}{|c|c|c|c|c|c|c|c|c|c|c|c|c|c|}
\hline \multirow{3}{*}{ Compostos } & \multirow{3}{*}{ T.R. } & \multicolumn{12}{|c|}{ Frações } \\
\hline & & \multicolumn{4}{|c|}{ Livre (mg/ $\mu \mathrm{L})$} & \multicolumn{4}{|c|}{ Solúvel (mg/L) } & \multicolumn{4}{|c|}{ Insolúvel (mg/ $\mu \mathrm{L}$ ) } \\
\hline & & M & C & ED & MT & M & C & ED & MT & M & $C$ & ED & MT \\
\hline Catecol & 3,20 & 0,07 & - & - & - & 0,11 & 0,35 & 0,11 & 0,20 & 0,14 & 0,23 & 0,30 & 0,12 \\
\hline Hidroquinona & 3,89 & - & 0,06 & - & - & - & - & - & - & - & - & - & - \\
\hline Gliciteína & 5,32 & - & - & - & - & - & 0,30 & 0,18 & 0,38 & 0,20 & 0,22 & 0,10 & 0,25 \\
\hline Salicílico & 5,42 & 28,70 & 5,87 & 14,39 & 14,84 & 33,51 & 45,88 & 22,33 & 20,88 & 4,95 & 4,60 & 8,01 & 4,28 \\
\hline Glictina & 5,60 & - & - & - & - & - & 0,07 & 0,08 & - & - & - & - & 0,05 \\
\hline Trans-cinamico & 5,89 & 0,18 & 0,04 & 0,09 & 0,09 & 0,17 & 0,24 & 0,12 & - & - & - & - & - \\
\hline Pirogalol & 6,03 & - & - & 0,41 & 0,50 & 0,11 & 0,21 & 0,12 & 0,12 & - & - & 0,11 & - \\
\hline p-hidroxibenzóico & 7,29 & - & - & - & - & 0,16 & 0,31 & 0,07 & - & - & - & - & - \\
\hline Gentíssico & 10,21 & - & - & - & - & - & - & 0,04 & - & - & - & - & - \\
\hline p-cumárico & 10,70 & - & - & - & - & - & - & 0,09 & - & - & - & - & - \\
\hline Protocatequínico & 11,02 & - & 0,23 & - & - & 0,07 & 0,12 & - & - & - & - & - & - \\
\hline p-cumárico & 12,20 & - & - & 0,94 & 1,10 & - & - & - & - & - & - & - & - \\
\hline Silibinina & 13,19 & - & - & - & - & - & - & - & - & - & - & - & - \\
\hline Gálico & 13,71 & - & - & 0,21 & 0,16 & 0,08 & - & - & - & - & - & - & - \\
\hline Ferúlico & 15,97 & 0,12 & - & 0,13 & - & - & - & - & - & - & - & - & - \\
\hline Caféico & 16,88 & 0,12 & 0,04 & 0,15 & 0,15 & 0,35 & 0,96 & 0,51 & 1,11 & 0,52 & 0,64 & 0,99 & 0,69 \\
\hline Sináptico & 18,65 & 0,42 & - & 1,76 & 0,96 & 0,08 & - & 0,06 & 0,02 & - & - & - & - \\
\hline Rutina & 24,13 & 0,06 & - & - & - & 0,03 & - & - & - & - & - & - & - \\
\hline Reveratrol & 26,12 & - & - & - & - & - & 0,02 & - & - & - & - & - & - \\
\hline Naringerina & 28,17 & - & 0,09 & - & - & - & - & - & - & - & - & - & - \\
\hline Epicatequina (-) & 28,37 & - & 0,04 & - & - & - & - & - & - & - & - & - & - \\
\hline Catequina & 28,71 & - & 0,11 & - & - & - & - & - & - & - & - & - & - \\
\hline Hesperitina & 29,35 & - & 0,06 & - & - & - & - & - & - & - & - & - & - \\
\hline Epilocatequina & 29,50 & 0,35 & - & - & 0,15 & - & - & - & - & - & - & - & - \\
\hline Clorogênico & 31,87 & 0,05 & - & - & - & - & - & - & - & - & - & - & - \\
\hline
\end{tabular}

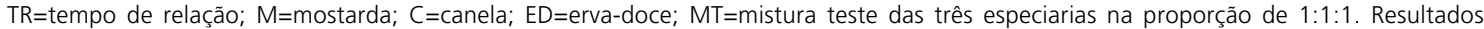
expressos em média de 5 repetições. 
Tabela 3. Resultados do ensaio biológico. Coeficiente de eficácia alimentar, absorção aparente de fenólicos, peroxidação e perfil de ácidos graxos essenciais.

\begin{tabular}{|c|c|c|c|c|c|}
\hline \multirow{3}{*}{ Constituintes } & \multicolumn{5}{|c|}{ Grupos } \\
\hline & \multicolumn{2}{|c|}{$\omega 3$} & \multicolumn{3}{|c|}{$\omega 6$} \\
\hline & Controle & Experimental & Controle & \multicolumn{2}{|c|}{ Experimental } \\
\hline Coeficiente de eficácia alimentar & $0,69 \pm 0,02$ & $0,63 \pm 0,01$ & $0,68 \pm 0,03$ & 0,67 & $\pm 0,02$ \\
\hline Absorção aparente de fenólicos* & - & $73,73 \pm 0,50$ & - & 72,94 & $\pm 0,70$ \\
\hline Peroxidação** & $\omega 3 C$ & $\omega 3 \mathrm{E}$ & $\omega 6 \mathrm{C}$ & \multicolumn{2}{|r|}{$\omega 6 \mathrm{E}$} \\
\hline plasma & $0,396 \pm 0,06$ & $0,309 \pm 0,06$ & $0,850 \pm 0,08$ & 0,257 & $\pm 0,03$ \\
\hline fígado & $0,870 \pm 0,06$ & $0,621 \pm 0,11$ & $0,761 \pm 0,09$ & 0,485 & $\pm 0,05$ \\
\hline cérebro & $1,767 \pm 0,161$ & $1,080 \pm 0,10$ & $1,127 \pm 0,09$ & 0,953 & $\pm 0,12$ \\
\hline coração & $1,154 \pm 0,10$ & $0,933 \pm 0,15$ & $1,000 \pm 0,07$ & 0,630 & $\pm 0,09$ \\
\hline tecido adiposo & $0,725 \pm 0,08$ & $0,330 \pm 0,01$ & $1,225 \pm 0,14$ & 0,950 & $\pm 0,11$ \\
\hline rins & $0,723 \pm 0,87$ & $0,295 \pm 0,02$ & $0,468 \pm 0,08$ & 0,295 & $\pm 0,02$ \\
\hline \multirow[t]{2}{*}{ Ácido graxos essenciais** } & \multirow[t]{2}{*}{$\omega 3 C$} & $\omega 3 \mathrm{E}$ & $\omega 6 \mathrm{C}$ & \multicolumn{2}{|r|}{$\omega 6 \mathrm{E}$} \\
\hline & & & Ácido linoléico & & \\
\hline \multirow[t]{2}{*}{ Tecido cardíaco } & \multirow[t]{2}{*}{-} & \multirow[t]{2}{*}{-} & $15,00 \pm 1,40$ & 45,70 & $\pm 1,90$ \\
\hline & & & \multicolumn{3}{|l|}{ Ácido araquidônico } \\
\hline Tecido hepático & - & - & $17,05 \pm 2,22$ & 21,08 & $\pm 2,22$ \\
\hline \multirow[t]{2}{*}{ Tecido plasmático } & - & - & $21,20 \pm 2,46$ & 26,56 & $\pm 2,00$ \\
\hline & \multicolumn{2}{|l|}{ EPA } & & & \\
\hline Tecido cerebral & $0,00 \pm 0,00$ & $9,10 \pm 0,40$ & - & & - \\
\hline \multirow[t]{2}{*}{ Tecido renal } & $6,90 \pm 1,30$ & $5,30 \pm 10,90$ & - & & - \\
\hline & \multicolumn{2}{|l|}{ DHA } & & & \\
\hline Tecido cerebral & $13,6 \pm 0,60$ & $5,30 \pm 0,60$ & - & & - \\
\hline Tecido renal & $5,30 \pm 0,20$ & $10,90 \pm 1,20$ & - & & - \\
\hline
\end{tabular}

(*) Absorção aparente (AbAp) de fenólicos nas fezes dos animais experimentais. AbAp foi obtida pela expressão: [(fenólicos consumidos-fenólicos fecais)/fenólicos ingeridos] x 100. Dados aquiridos em triplicada da coleta realizada durante as 5 semanas de tratamento com o chá, em concentração de 200 ppm, administrado a cada animal por gavagem.; ${ }^{(* *)}$ Dados expressos em mg de proteína por mMol de MDA; ${ }^{(* * *)}$ Incorporação de ácidos graxos essenciais. Dados em percentual de incorporação.

O perfil de incorporação do ácido linoléico é refletido no percentual do $A A$, visto que este ácido graxo é elongado e dessaturado a partir da presença dietética do ácido linoléico. Verifica-se, portanto, o mesmo comportamento dos grupos controle e experimental quanto ao percentual de incorporação do ácido linoléico nos tecidos avaliados. Todavia, para o tecido renal, houve uma inversão de valores do AA em relação ao ácido linoléico, quando comparados o grupo experimental com seu respectivo controle. Neste tecido, o grupo experimental apresentou um perfil de incorporação de 8,80\% em comparação ao controle, de 5,30\% (Tabela 3).

No EPA presente, principalmente, na ração rica em óleo de peixe, observou-se um percentual de incorporação, sem diferença significativa entre os grupos controle e experimental, para os tecidos plasmático, hepático, cardíaco e adiposo. Porém, para o tecido cerebral que utiliza preferencialmente este ácido graxo, houve diferença significativa nos percentuais de incorporação entre os grupos experimental e de controle, com uma média de $9,10 \%$ e $0 \%$, respectivamente. Estes dados dão indícios de haver um fator protetor no grupo experimental, que pode ter sido fornecido pelo chá rico em substâncias fenólicas. O chá foi a única variável diferencial na alimentação dos grupos controle e experimental (Tabela 3).

Entretanto, para o DHA, presente na ração à base de óleo de peixe, foi verificado um percentual de incorporação diferenciado para os 
tecidos dos animais dos grupos controle e experimental (Tabela 3).

Estes resultados demonstraram que os tecidos possuem comportamentos distintos quanto à incorporação dos diferentes ácidos graxos, quando estão associados à ingestão de antioxidantes, levando-se a inferir, que há uma relação direta entre a presença de antioxidantes e a incorporação tecidual dos ácidos graxos.

Houve diferenças nos percentuais de incorporação dos diferentes ácidos graxos nos tecidos dos animais que receberam ora a ração à base de óleo de soja, ora à base de peixe; quando comparados os grupos experimentais (chá) e controles (placebo), essas diferenças se refletiram no somatório global dos ácidos graxos saturados, monoinsaturados e poliinsaturados.

A presença de lípides essenciais na dieta deveu-se à importância dos mesmos sobre a biossíntese dos eicosanóides, que pode ocorrer: 1) via COX, responsável pela transformação cíclica do AA a prostaglandinas e tromboxanos das séries 2; ou 2) via LOX, que cataliza de maneira linear as transformações dos substratos do AA para formação de leucotrienos. A via COX pode ser inibida por indomentacina e outros agentes antiinflamatórios, como a aspirina e o ácido acetil salicílico.

Destacado o percentual de inibição do chá da mistura das especiarias nas concentrações 100 e 200 ppm (dados destacados na Figura 1A), foi possível delinear o ensaio de inibição das enzimas lipoxigenase e cicloxigenase. Observou-se então, que a mistura das especiarias mostarda, canela e erva-doce, foi capaz de inibir em torno de $74 \%$ estas enzimas, com efeitos equivalentes aos da indomentacina, utilizada como inibidor conhecido de COX e controle positivo da reação. O mesmo foi observado no ensaio de inibição via LOX, no qual o mesmo extrato foi capaz de inibir estas enzimas, que permaneceram apenas com uma média de $10 \%$ de sua atividade (Figuras 1B e 1C). Estatisticamente, foram construídas tabelas de medidas descritivas, onde graficamente se demonstraram os resultados obtidos em 3 ensaios com 5 repetições, que apresentaram médias com diferença significativa entre o controle positivo (presença de um inibidor) e o controle negativo (sem presença de inibidor). Já para a variável chá tanto na concentração de 100 como na de 200 ppm (melhor atividade atioxidante no sistema $\beta$-caroteno), não apresentou diferença significativa para o controle positivo. Os dados apresentaram alta repetibilidade e reprodutividade, verificando-se que os valores mínimos e máximos das medianas obtidas apresentaram o mesmo valor, com ausência de desvio-padrão.

Vale ressaltar a importância dos alimentos para a manutenção da saúde, assim como mostra a dieta do mediterrâneo. Esta dieta é rica em frutas, vegetais, grãos e óleos derivados de plantas, especialmente o azeite de oliva. Embora o efeito protetor de tal dieta seja de caráter multifatorial, como o consumo proporcional de lípides saturados e poliinsaturados, destacam-se nela a presença de vários vegetais, incluindo especiarias, vinho tinto e chás. Estes últimos caracterizam-se pela presença de substâncias fenólicas (derivadas do ácido cinâmico, como o ácido caféico), que refletem na baixa oxidação de constituintes lipídicos, prevenindo o desenvolvimento de doenças degenerativas, como a aterosclerose. Este efeito ocorre em função da ação sobre mediadores inflamatórios, ou seja, compostos fenólicos que agem inibindo as enzimas que formam eicosanóides a partir do AA.

A influência dos componentes alimentares na dieta mostrou-se importante para o desenvolvimento dos animais (Figura 2) que apresentaram um bom coeficiente de eficácia alimentar (Tabela 3).

Outro fator importante avaliado foi o ganho de peso dos animais (Figura 2). A análise estatística da variável ganho de peso foi realizada por meio do teste " $t$ " e intervalo de confiança para a diferença de médias entre grupo controle e experimental. Observou-se que, para os animais suplementados com dieta $\omega 3$ e o infuso contendo antioxidantes naturais (grupo experimental), o 
ganho médio de peso foi menor do que o daquele dos animais que ingeriram somente a dieta $\omega 3 \mathrm{e}$ o placebo (grupo controle). Entre os animais que receberam dieta $\omega 6$, o teste não detectou diferença entre os ganhos médios de peso dos grupos controle e experimental.
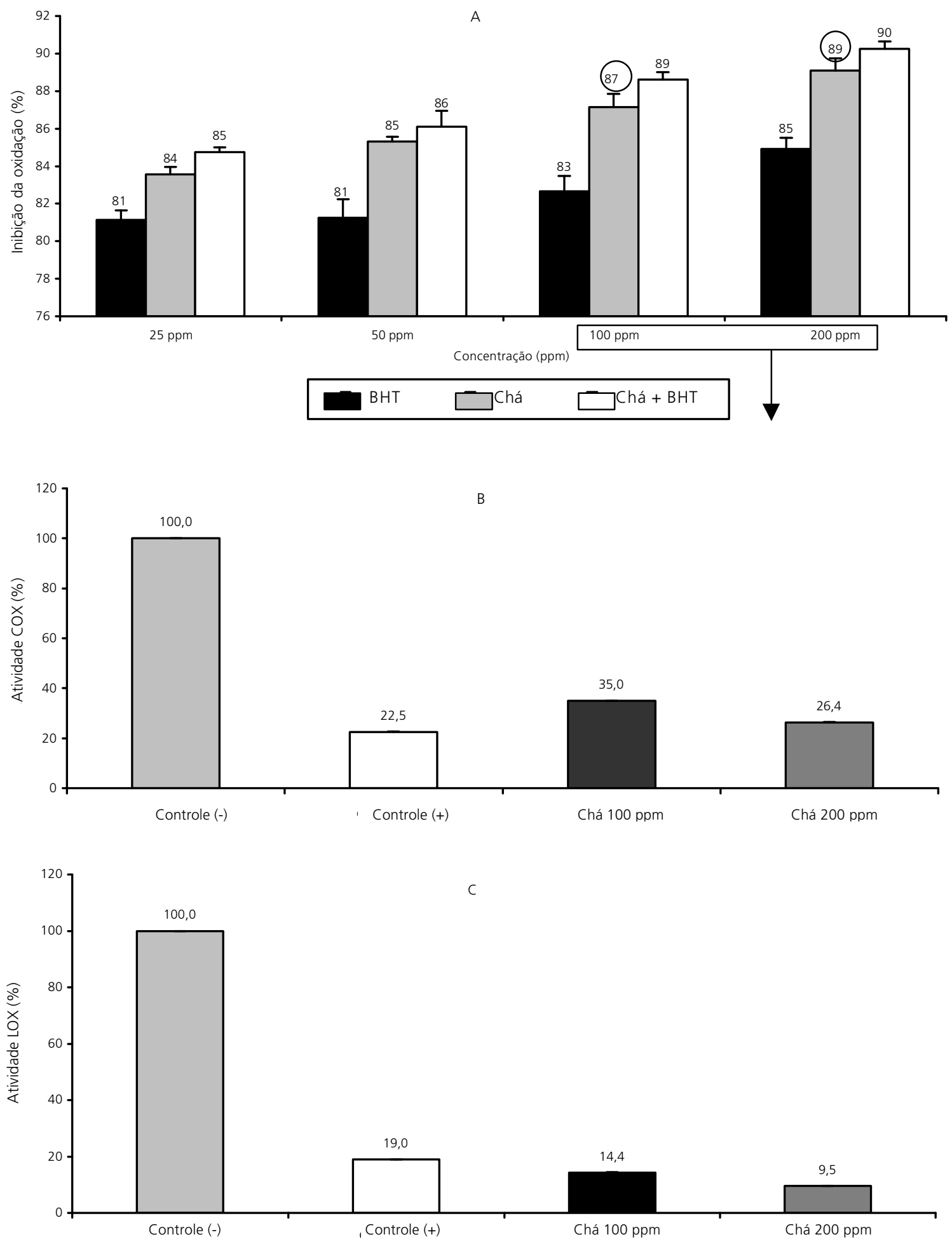

Figura 1. A-Atividade antioxidante do chá da mistura das especiarias. 


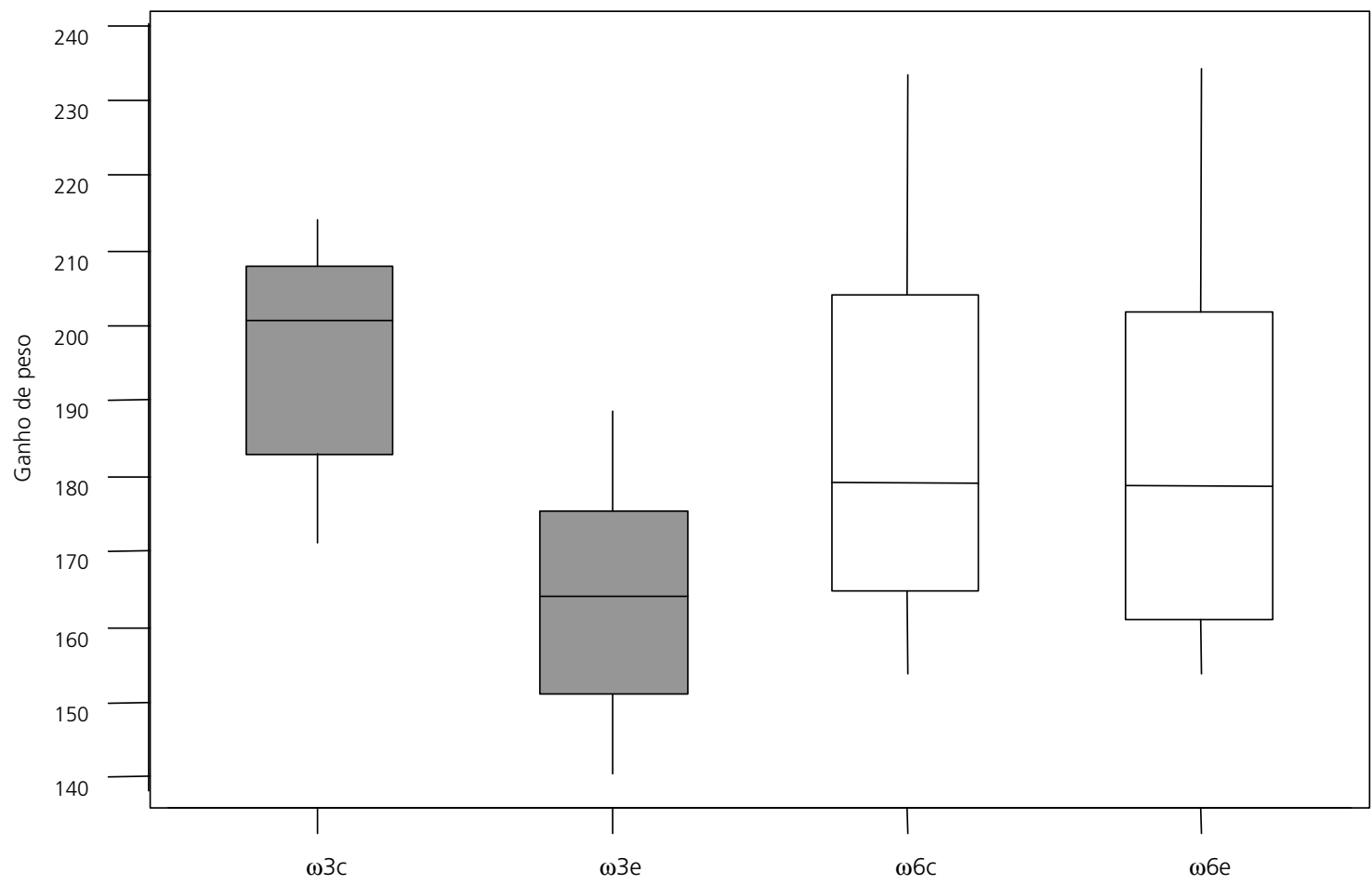

Figura 2. Box-plot do desenvolvimento dos animais.

Diante da diferença de peso entre o grupo $\omega 3$ experimental e o seu respectivo controle, foi investigado um provável efeito antinutricional do chá oferecido aos animais experimentais, visto esta ser a única variável diferenciada entre os grupos. Observou-se que a presença de compostos fenólicos não alterou a morfologia intestinal dos animais, de maneira a refletir-se no crescimento dos mesmos.

Observou-se, porém, que estes animais dos grupos do infuso experimental, tiveram um peso médio do tecido adiposo subcutâneo de 25\% menor do que os pesos dos tecidos adiposos subcutâneos (visceral) dos respectivos grupos controles. Isto poderia também explicar a diminuição da curva de crescimento destes animais, visto que o consumo destes grupos não apresentou diferença significativa, como se observa pelo coeficiente de eficácia alimentar apresentado nos dados da Tabela 3. Esta diferença no tecido adiposo, merece investigação para comprovar um provável efeito dos compostos fenólicos sobre o metabolismo adiposo.

Várias pesquisas com substâncias fenólicas de plantas tinham sido ignoradas até o estudo de Hertog et al. ${ }^{22}$, que infere que a causa de doenças crônico-degenerativas, como aterosclerose e câncer, pode ser o resultado de uma série de alterações em alimentos e organismos vivos desencadeadas pelo processo oxidativo. Desta forma, antioxidantes naturais, tais como os compostos fenólicos de plantas, podem atuar na inibição da oxidação, patogenicidade de doenças e produção de eicosanóides.

Considerando a atuação dos compostos fenólicos de plantas, principalmente de especiarias, misturas têm sido elaboradas para encontrar um perfil sensorial e químico que permita sua efetividade nos alimentos ou em organismos vivos.

Foi verificado o potencial antioxidante da mistura das especiarias: mostarda, canela e 
erva-doce; os resultados obtidos sugerem uma provável atuação sobre o metabolismo lipídico, por meio de proteção contra a oxidação e ação sobre enzimas da biossíntese dos eicosanóides.

O extrato das especiarias inibiu tanto a COX como a LOX, limitando, portanto, a formação de eicosanóides; isto pode ter um efeito indireto na inibição do processo inflamatório, além de um efeito antioxidante generalizado; tais compostos podem também inibir a patogênese de doenças ainda mais complexas, tais como AIDS, câncer, aterosclerose e diabetes ${ }^{17}$. Pesquisa recente, realizada por McKay \& Blumberg ${ }^{23}$, apontou para a ação direta de substâncias fenólicas presentes em chás de especiarias sobre a saúde humana, atuando sobre doenças crônicas; ação reforçada pelo potencial antioxidante destas substâncias naturais.

\section{O N CLUSÃO}

As especiarias, cuja história se confunde com a da indústria alimentícia, podem atuar tanto sobre alimentos potencialmente funcionais, prevenindo contra o processo oxidativo, como sobre o organismo vivo, protegendo ou agindo como agentes terapêuticos para doenças de resposta inflamatória.

Além da ação preventiva de substâncias fenólicas, presentes nas especiarias, sobre a oxidação lipídica em alimentos, os resultados obtidos sugerem, também, um provável efeito antinflamatório destes compostos, devido à ação inibitória sobre enzimas da biossíntese dos eicosanóides. Por outro lado, maiores investigações e ensaios biológicos mais abrangentes são necessários, para que outras conclusões possam ser tiradas a respeito da atuação dos compostos fenólicos de especiarias sobre o metabolismo lipídico e para assegurar-nos do efeito delas como alimento funcional.

\section{REFERÊ N CIAS}

1. Ziboh VA, Miller CC, Cho Y. Metabolism of polyunsaturated fatty acids by skin epidermal enzymes: Generation of antiinflammatory and antiproliferative metabolites. Am J Clin Nutr 2000; 7:361-6

2. Moncada S, Vane JR. Unstable metabolites of arachidonic acid and their role in haemostasis and thrombosis. Br Med Bull 1978; 34:129.

3. Dyerberg J, Bang HO, Stoffersen E, Moncada S, Vane JR. Eicosapentaenoic acid and prevention of thrombosis and atherosclerosis. Lancet 1978; 2:117.

4. Moroney MA, Alcaraz MJ, Forder RA, Carey F, Hoult RS. Selectivity of Neutrophil 5-lipoxygenase and cyclo-oxygenase inhibition by na anti-inflamatory flavanoid glycoside and related aglycone flavonids. J Pharm Pharmacol 1988; 40:787-92.

5. Madsen HL, Bertelsen G. Spices as antioxidants. Trends Food Sci Tech 1995; 61:271-7.

6. Madsen HL, Nielsen BR, Bertelsen G, Skibsted LH. Screening of antioxidative activity of spices. A comparison between assays based on ESR spin trapping and electrochemical measurement of oxygen consumption. Food Chem 1996; 57(2):331-7.

7. Vinson JA, Dabbag YA. Tea phenols: Antioxidant effectiveness of teas, tea components, tea fractions and their binding with lipoproteins. Nutr Res 1998; 18:1067-107.

8. Guimarães ARP, Sitnik RH, Nascimento-Curi CMPO, Curi R. Polyunsaturated and saturated fatty acids-rich diet and immune tissues. Biochem Int 1990; 22:1005-13.

9. Association Official Analytical Chemists. Official methods of analysis of the AOAC. 13.ed. Washington D.C.; 1980. 858p.

10. Dubois M, Gilees KA, Hamilton JK, Ribers PA, Smith F. Colorimetric method for determination of sugars and relater substances. Anal Chem 1956; 28:350-6.

11. Swain T, Hills WE. The phenolic constituients of Punnus domestica. I. Quantitative analysis of phenolic constituints. J Sci Food Agric 1959; 19:63-8 
12. Miller HE. A simplified method for the evaluation of antioxidants. J Am Oil Chem Soc 1971; 48:91.

13. Folch J, Lees M, Stanley GHS. A simple method for the isolation and purification of total lipids. J Biol Chem 1957; 226:497.

14. Hartman L, Lago RCA. Rapid preparation of fatty acids methyl esters. Lab Pract 1973; 22:475-6.

15. Dabrowski KJ, Sosulski FW. Quantification of free an hydrolyzable phenolic acids in seeds by capillary gas-liquid chromatography. J Agric Food Chem 1984; 32:123-7.

16. Survey K. Spectrophotometric method for determination of lipoxygenase activity. Plant Physiol 1964; 39:65-70.

17. Schubert SY, Lansky EP, Neeman I. Antioxidant and eicosanoid enzyme inhibition properties of pomegranate oil and fermented juice flavonoids. J Ethnopharmacol 1999; 66:11-7.

18. Bradford MM. A rapid and sensitive method for the quantitation of microgram quantities of protein utilizing the principle of protein-dye binding. Anal Biochem 1985; 72:677-85.
19. Winterbourn CC, Gutteridge JM, Halliwel B. Doxorubicin-dependent lipid peroxidation at low partial pressures of $\mathrm{O}_{2}$. J Free Radical Biol Med $1985 ; 1: 43-9$.

20. Milos M, Mastelic J, Jerkovic I. Chemical composition and antioxidant effect of glycosidically bound volatile compounds from oregano (Origanum vulgare, L. ssp. hirtum). Food Chem 2000; 71:79-83.

21. Shahidi F, Wanasundara PKJPD. Phenolic antioxidants. Crit Rev Food Sci Nutr 1992; 32:67-103.

22. Hertog MG, Feskins FJ, Hollman PC, Katan MB, Kremhout D. Dietary antioxidant flavonoids and risk of coronary heart disease: The Zutphen Elderly stydy. Lancet 1993; 342:1007-11.

23. McKay DL, Blumberg JB. The role of tea in human health: An update. J Am Coll Nutr 2002; 21:1-13.

Recebido para publicação em 18 de fevereiro e aceito em 4 de dezembro de 2003. 